\title{
5-Lipoxygenase Is Located in the Euchromatin of the Nucleus in Resting Human Alveolar Macrophages and Translocates to the Nuclear Envelope Upon Cell Activation
}

John W. Woods, ${ }^{*}$ Michael J. Coffey, ${ }^{\star}$ Thomas G. Brock, ${ }^{\ddagger}$ Irwin I. Singer, ${ }^{\star}$ and Marc Peters-Golden ${ }^{\star}$

*Department of Biochemical and Molecular Pathology, Merck Research Laboratories, Rahway, New Jersey 07065; and ${ }^{\ddagger}$ Division of Pulmonary and Critical Care Medicine, Department of Internal Medicine, University of Michigan and Department of Veterans Affairs Medical Centers, Ann Arbor, Michigan 48105

\begin{abstract}
5-Lipoxygenase (5-LO) and 5-lipoxygenase-activating protein (FLAP) are two key proteins involved in the synthesis of leukotrienes (LT) from arachidonic acid. Although both alveolar macrophages (AM) and peripheral blood leukocytes (PBL) produce large amounts of $L T$ after activation, 5-LO translocates from a soluble pool to a particulate fraction upon activation of PBL, but is contained in the particulate fraction in $A M$ irrespective of activation. We have therefore examined the subcellular localization of 5-LO in autologous human AM and PBL collected from normal donors. While immunogold electron microscopy demonstrated little 5-LO in resting PBL, resting AM exhibited abundant 5-LO epitopes in the euchromatin region of the nucleus. The presence of substantial quantities of 5-LO in the nucleus of resting AM was verified by cell fractionation and immunoblot analysis and by indirect immunofluorescence microscopy. In both $A M$ and PBL activated by $A 23187$, all of the observable 5-LO immunogold labeling was found associated with the nuclear envelope. In resting cells of both types, FLAP was predominantly associated with the nuclear envelope, and its localization was not affected by activation with A23187. The effects of MK-886, which binds to FLAP, were examined in ionophore-stimulated AM and PBL. Although MK-886 inhibited LT synthesis in both cell types, it failed to prevent the translocation of 5-LO to the nuclear envelope. These results indicate that the nuclear envelope is the site at which 5-LO interacts with FLAP and arachidonic acid to catalyze LT synthesis in activated AM as well as PBL, and that in resting AM the euchromatin region of the nucleus is the predominant source of the translocated enzyme. In addition, LT synthesis is a two-step process consisting of FLAP-independent translocation of 5-LO to the nuclear envelope followed by the FLAP-dependent activation of the enzyme. (J. Clin. Invest. 1995. 95:2035-2046.) Key words: leukotrienes - leukocytes - 5-lipoxygenase-activating protein • immunoelectron microscopy • immunoblot analysis • immunofluorescence microscopy
\end{abstract}

Address correspondence to John W. Woods, Ph. D., Merck Research Laboratories, P.O. Box 2000, R80N-A43, Rahway, NJ 07065. Phone: 908-594-4001; FAX: 908-594-3111.

Received for publication 2 May 1994 and in revised form 28 October 1994.

The Journal of Clinical Investigation, Inc.

Volume 95, May 1995, 2035-2046

\section{Introduction}

Leukotrienes (LT) are mediators of inflammation with important roles in host defense as well as in the pathogenesis of such diseases as asthma, rhinitis, inflammatory bowel disease, psoriasis, and rheumatoid arthritis (1). The enzyme 5-lipoxygenase (5-LO) ${ }^{1}$ catalyzes the first two steps in the pathway by which arachidonic acid (AA) is converted to LT (2). Recent studies have elucidated some of the intracellular events involved in 5-LO activation in granulocytic cells. 5-LO resides in a soluble fraction of disrupted resting cells. Upon agonist stimulation, 5-LO undergoes a rapid $\mathrm{Ca}^{2+}$-dependent redistribution to a sedimentable fraction (3-5) where it can interact with an integral membrane-bound protein designated 5-LO-activating protein or FLAP (6). This interaction appears to be required for cellular LT synthesis from endogenous AA, as evidenced by studies with drugs that are FLAP inhibitors (7-9), as well as by transfection studies showing that osteosarcoma cells, which lack both proteins, were capable of LT synthesis only when they were cotransfected with the cDNAs for both 5-LO and FLAP (10). Although FLAP was originally proposed (11) to serve as a docking protein for translocated 5-LO, the precise nature of the 5-LO/FLAP interaction remains to be delineated.

Electron microscopic immunolocalization studies of 5-LO and FLAP in human polymorphonuclear leukocytes (PMN) and peripheral blood monocytes (PBM) were reported recently (12). Surprisingly, the nuclear envelope was shown to be the predominant site of FLAP localization, as well as the site of 5LO localization in ionophore-stimulated cells of both types. These results suggest that the nuclear envelope is the major intracellular site for LT synthesis.

In this study, we have investigated the localization of 5-LO and FLAP in human alveolar macrophages (AM). Our interest in AM is motivated by several observations. First, the AM is the major resident immune effector cell of the pulmonary alveoli and airways; as such, it represents the first line of defense of the lung against inhaled toxins and pathogens and is an important participant in the pathogenesis of a variety of inflammatory and immune disorders of the lung (13). Second, the capacity for 5LO metabolism in AM is substantially greater than that of other tissue macrophage populations (14), and of the PBM (15-17), its circulating precursor. Third, unlike PMN or PBM, $~ 50 \%$ of the total immunoreactive 5-LO was reported to be associated with the $100,000 \mathrm{~g}$ pellet in resting AM derived from both humans (18) and rats (19). Although large quantities of LT

1. Abbreviations used in this paper: AM, alveolar macrophages; FLAP, 5-LO-activating protein; 5-LO, 5-lipoxygenase; PBL, peripheral blood leukocytes; PBM, peripheral blood monocytes. 
were synthesized upon ionophore activation of these cells, no further redistribution of 5-LO into a sedimentable fraction beyond that which was present in resting cells could be discerned (19).

We have sought to answer the following specific questions: (a) Is the nuclear envelope the subcellular membrane site of FLAP and 5-LO localization in the ionophore-stimulated AM, as was observed in PMN and PBM?; (b) Does the sedimentable pool of 5-LO in resting AM reflect the same intracellular site of localization as in ionophore-stimulated cells?; and (c) What is the effect of the FLAP inhibitor MK-886 on 5-LO distribution in stimulated AM? For the purposes of comparison, we also carried out parallel studies on autologous circulating peripheral blood leukocytes (PBL), comprised of both PMN and PBM, obtained from the same donors.

\section{Methods}

Materials. Ficoll-Paque and Percoll were obtained from Pharmacia LKB Biotechnology (Piscataway, NJ); dextran T500 was from Pharmacia AB (Uppsala, Sweden); Dulbecco's PBS either with or without calcium and magnesium, medium 199, and ACK lysis buffer were from Gibco Laboratories (Grand Island, NY). Lymphocyte separation medium was from Organon Teknika (Durham, NC). Colloidal gold probes $(5 \mathrm{~nm}$ ) conjugated with goat anti-rabbit IgG (GAR5), rainbow molecular weight markers, horseradish peroxidase-conjugated anti-rabbit IgG, and reagents for chemiluminescent detection of immunoblots were purchased from Amersham Corp. (Arlington Heights, IL). Sea Plaque low gelling temperature agarose was obtained from FMC Corp. BioProducts (Rockland, ME). Glutaraldehyde and osmium tetroxide were from Electron Microscopy Sciences (Fort Washington, PA). Paraformaldehyde was from Fisher Scientific (Fair Lawn, NJ), and A23187 was from Calbiochem-Novabiochem (La Jolla, CA). Dimethylsulfoxide (DMSO) and rhodamine-conjugated goat anti-rabbit IgG were from Sigma Chemical Co. (St. Louis, MO). Ketamine was from Aveco Co. (Fort Dodge, IA), and xylazine was from Mobay Corp. (Shawnee, KS). Kits for total protein determination were from Pierce Chemical Co. (Rockford, IL). Nitrocellulose membranes were obtained from Bio-Rad Laboratories (Richmond, CA). Other chemicals were of reagent grade and were obtained from Sigma Chemical Co. MK-886, L-583,916, and peptides corresponding to FLAP amino acids 41-52 and 102-118 were provided by Dr. Jilly Evans and Dr. Philip Vickers (Merck Frosst, Pointe Claire-Dorval, Canada). Rabbit polyclonal antisera to purified 5-LO, FLAP amino acids 41-52, and LTA hydrolase were also provided by Dr. Jilly Evans and Dr. Philip Vickers. Recombinant 5-LO was provided by Dr. Denis Riendeau (Merck Frosst).

Isolation of human $A M$ and $P B L$. Three normal nonsmoking volunteers (mean age $\pm S E M, 26 \pm 2.5 \mathrm{yr}$ ) comprised the subjects for this study. All were free of lung disease and recent medication use. Informed consent was obtained according to the guidelines of the Human Use Committee of the University of Michigan Medical Center. AM were obtained by bronchoalveolar lavage as described previously (15). Briefly, subjects were premedicated with an intramuscular injection of $1 \mathrm{mg}$ atropine sulfate, after which anesthesia of the nasal, pharyngeal, and laryngeal mucosa was achieved with topical lidocaine. A fiberoptic bronchoscope (BF-2TR; Olympus, Lake Success, NY) was inserted nasally, and after application of $2 \%$ lidocaine to the tracheobronchial mucosa was sequentially wedged into subsegmental bronchi of the right middle lobe and lingula. Bronchoalveolar lavage was performed at each site by injecting $360-\mathrm{ml}$ aliquots of room temperature $0.9 \% \mathrm{NaCl}$. The fluid was collected in sterile traps by gentle suction. AM comprised $>90 \%$ of lavaged cells as judged by nonspecific esterase staining; viability, assessed by exclusion of trypan blue, exceeded $92 \%$.

Autologous PBL were isolated from heparinized whole blood. Blood was diluted with an equal volume of $0.9 \% \mathrm{NaCl}$, and $25 \mathrm{ml}$ of the blood-saline (1:1, vol/vol) mixture was layered over Ficoll-Paque and centrifuged at $400 \mathrm{~g}$ for $30 \mathrm{~min}$ at $23^{\circ} \mathrm{C}$. The mononuclear cell layer at the gradient interface was removed, pelleted, and hypotonic lysis performed to remove contaminating red blood cells (20). Platelets were removed by centrifuging the mononuclear cells in ice cold calcium- and magnesium-free PBS containing $0.1 \%$ gelatin at $400 \mathrm{~g}$ for $15 \mathrm{~min}$ at $4^{\circ} \mathrm{C}$. Percoll (density 1.065 ) gradient centrifugation $(800 \mathrm{~g}$ for $20 \mathrm{~min}$ at $23^{\circ} \mathrm{C}$ ) was performed to separate PBM from lymphocytes. The upper fraction contained $>88 \%$ PBM, as assessed by nonspecific esterase staining. PMN were obtained from the lower cell layer resulting from the Ficoll-Paque centrifugation step. This layer was subjected to dextran sedimentation, and contaminating red blood cells were removed by hypotonic lysis; the remaining cells were centrifuged, washed, and resuspended in calcium- and magnesium-free PBS The resulting cell suspension consisted of $98 \%$ PMN as determined by Diff-Quik staining (19). Finally, PBM and PMN were combined together in the original ratios present in blood in order to yield PBL. Viability of each cell type exceeded $92 \%$.

Isolation of rat AM. Respiratory disease-free female Wistar rats weighing 125-150 g were obtained from Charles River Labs (Portage, MI) and housed under specific pathogen-free conditions. Animals were anesthetized by subcutaneous injection of $0.5 \mathrm{ml}$ of a $1: 1$ mixture of ketamine and xylazine. Lung lavage was performed as described (14), and resident $\mathrm{AM}$ comprised $\sim 93 \%$ of the lavage cell population as determined by nonspecific esterase staining.

Experimental incubations. Cells $\left(\sim 5 \times 10^{6} \mathrm{AM}\right.$ or $\left.15 \times 10^{6} \mathrm{PBL}\right)$ suspended in $5 \mathrm{ml}$ of medium 199 were incubated for $5 \mathrm{~min}$ in polypropylene tubes in the presence of either $5 \mu \mathrm{g} / \mathrm{ml} \mathrm{A23187} \mathrm{(in} \mathrm{0.1 \%} \mathrm{DMSO)}$ or DMSO vehicle alone. In selected experiments, cells were preincubated for $5 \mathrm{~min}$ with the FLAP inhibitor MK-886 $(1 \mu \mathrm{M})$ or its inactive analogue L-583,916 at the same concentration before activation with A23187. Cell-free supernatants were collected and frozen at $-20^{\circ} \mathrm{C}$ for subsequent quantitation of $\mathrm{LTB}_{4}$ by radioimmunoassay as described previously (15). Cells were fixed and processed for immunogold electron microscopy as described below.

Fixation and freezing of cells. After experimental incubations and removal of cell-free supernatants as described above, cells were resuspended in $2.5 \mathrm{ml}$ of ice-cold PBS. These cell suspensions were fixed, embedded in agar, cryoprotected, and frozen exactly as has been described previously (12). In brief, cells were initially fixed by microwave irradiation (21) in $0.05 \%$ glutaraldehyde, $3.5 \%$ paraformaldehyde, 0.1 $\mathrm{M}$ sucrose in PBS, pH 7.3. After this initial fixation, cells were washed in paraformaldehyde-lysine-periodate (PLP) fixative (22) and fixation was continued in PLP overnight at $4^{\circ} \mathrm{C}$. The fixed cells were divided into aliquots and pelleted through liquefied agarose, typically 3-6

Figure 1. Immunogold labeling of ultrathin frozen sections of resting AM incubated with anti-5-LO IgG ( $A$ and $C$ ) or anti-FLAP IgG (B and $D)$. In $C$ and $D$, the primary antibody incubations were carried out in the presence of competing excess free antigen. Note that 5-LO label (arrowheads, $A$ ) is found throughout the euchromatin region of the nucleus ( $n u c$, lighter areas) and appears to be excluded from the heterochromatin region (darker areas), whereas the FLAP immunogold label (arrowheads, $B$ ) is associated with the nuclear envelope ( $n e$ ) and is not observed within the nucleus itself. With either antibody a few gold particles are also localized over the endoplasmic reticulum (er). Neither probe appears to associate with the plasma membrane ( $\mathrm{pm}$ ) or with mitochondria (mito). The specificity of labeling is demonstrated by the absence of detectable gold particles in $C$, in which $10 \mathrm{mg} / \mathrm{ml}$ anti-5-LO IgG was incubated with the section in the presence of $100 \mathrm{mg} / \mathrm{ml}$ competing free recombinant 5-LO, and in $D$, in which $10 \mathrm{mg} / \mathrm{ml}$ anti-FLAP peptide IgG was incubated with the section in the presence of $100 \mathrm{mg} / \mathrm{ml}$ competing free peptide. Bar, $100 \mathrm{~nm}$. 

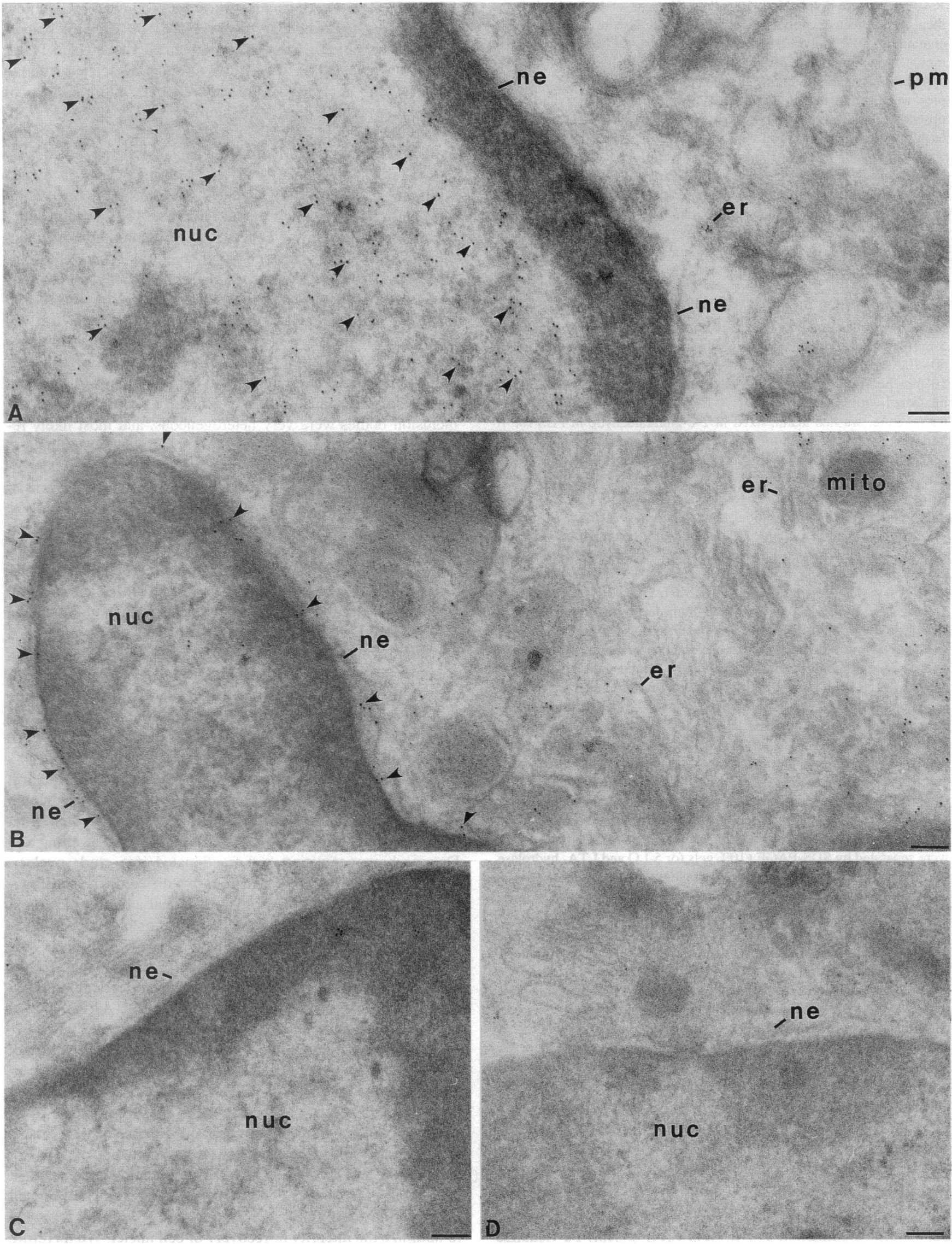
$\times 10^{6}$ cells were divided into 10 pellets. The agar-embedded cells were then cryoprotected with $2.3 \mathrm{M}$ sucrose in phosphate buffer, $\mathrm{pH} 7.2$, containing $50 \%$ polyvinylpyrrolidone (23), after which they were mounted on aluminum nails and frozen using a Reichert KF-80 freezing apparatus (Reichert Scientific Instruments, Buffalo, NY). Frozen samples were stored under liquid nitrogen until use. Each experimental observation was verified by sectioning at least two different pellets of each prefixation treatment of cells isolated from three different donors.

Immunogold labeling of cryosections. Immunogold labeling was carried out as described previously (12). In brief the protocol was as follows: ultrathin cryosections were prepared as described by Tokuyasu (24) on a Reichert Ultracut S ultramicrotome equipped with an FCS cryoattachment. Sections were transferred to nickel grids and incubated for $2 \times 10$ min with $1 \%$ bovine serum albumin (BSA) in PBS containing $0.02 \% \mathrm{Na}$ azide (BSA/PBS) to block nonspecific binding, the sections were then incubated overnight at $4^{\circ} \mathrm{C}$ with primary antibody solutions at $10 \mu \mathrm{g} / \mathrm{ml}$ in BSA/PBS. To demonstrate specificity, in certain experiments the primary antibodies were preincubated with either recombinant 5-LO or the peptide corresponding to amino acids 41-52 of FLAP at $50-100 \mu \mathrm{g} / \mathrm{ml}$ for $30 \mathrm{~min}$ followed by centrifugation at $10,000 \mathrm{~g}$ for $10 \mathrm{~min}$ before incubation. The next morning, sections were washed, incubated with GAR5 (diluted 1:50 in BSA/PBS) for $60 \mathrm{~min}$ at room temperature, washed again, fixed in $2 \%$ glutaraldehyde in PBS for 10 min, postfixed in $2 \%$ osmium in $\mathrm{H}_{2} \mathrm{O}$ for 20 min, stained with $2 \%$ uranyl acetate in $\mathrm{H}_{2} \mathrm{O}$ for $30 \mathrm{~min}$, and finally absorption stained with $0.002 \%$ lead citrate in $2 \%$ polyvinylalcohol as described by Tokuyasu (23). Grids were examined and micrographs taken in a JEOL $100 \mathrm{CX}$ electronmicroscope at $80 \mathrm{kV}$ at an initial magnification of 19,000.

Cell fractionation and immunoblot analysis. Resting or A23187 activated human AM, human PBM, human PMN, or rat AM were washed in PBS, resuspended at $10^{7}$ cells $/ \mathrm{ml}$ of ice-cold $40 \%$ TKM buffer (TKM buffer: $50 \mathrm{mM}$ Tris- $\mathrm{HCl}, \mathrm{pH} 7.4,25 \mathrm{mM} \mathrm{KCl}, 5 \mathrm{mM} \mathrm{MgCl}$ ), containing $1 \mathrm{mM}$ each of phenylmethylsulfonyl fluoride, dithiothreitol, soybean trypsin inhibitor, and leupeptin, and incubated on ice for $10 \mathrm{~min}$. The swelled cells were disrupted by Dounce homogenization on ice with 50 strokes. The homogenate was immediately diluted with 3 vol of 0.25 $\mathrm{M}$ sucrose-TKM and centrifuged at $1,000 \mathrm{~g}$ for $10 \mathrm{~min}$ at $4^{\circ} \mathrm{C}$. The lowspeed pellet was washed in the same solution and repelleted to generate the crude nuclear fraction. The low-speed supernatant was centrifuged at $100,000 \mathrm{~g}, 4^{\circ} \mathrm{C}$, for $1 \mathrm{~h}$. The high-speed supernatant was designated cytosolic fraction, and the pellet was rinsed gently with TKM buffer and resuspended in the same buffer to yield the crude membrane fraction. Cell fractions were sonicated and their total protein content determined using a microtiter plate modification of the Bradford method with BSA as standard. Aliquots of fractions containing $\sim 20 \mu \mathrm{g}$ total protein were separated by SDS-PAGE ( $10 \%$ gels for 5-LO and $\mathrm{LTA}_{4}$ hydrolase, $15 \%$ gels for FLAP) and transferred to nitrocellulose membranes as described previously (19). Membranes were incubated with primary antisera (at titers of 1:3,000 for 5-LO and $\mathrm{LTA}_{4}$ hydrolase and 1:5,000 for FLAP) and horseradish peroxidase-conjugated anti-rabbit IgG $(1: 5,000)$, and proteins of interest were visualized using chemiluminescent detection.

Indirect immunofluorescence microscopy. Resting and activated human $\mathrm{AM}$ were fixed in $-20^{\circ} \mathrm{C}$ methanol for $30 \mathrm{~min}$, mounted on slides using a Cytospin ( $500 \mathrm{rpm}, 1 \mathrm{~min}$ ), acetone permeabilized, and blocked with 1\% BSA in PBS. Anti-5-LO antiserum was diluted 1:50 in 1\% BSA-PBS and applied for $1 \mathrm{~h}$ at $37^{\circ} \mathrm{C}$. Specimens were washed three times with $1 \%$ BSA-PBS, and rhodamine-conjugated goat anti-rabbit secondary antibody was added at $1: 64$ for $1 \mathrm{~h}$ at $37^{\circ} \mathrm{C}$. Slides were then examined at a magnification of $\mathbf{4 0}$ with a Nikon Labophot microscope equipped for epifluorescence.

\section{Results}

Subcellular localization of 5-LO and FLAP in AM. To visualize the intracellular distribution of FLAP and 5-LO in resting human AM, ultrathin cryosections of frozen cells were incubated with either anti-FLAP or anti-5-LO IgG followed by colloidal gold-conjugated secondary probes (Fig. 1). Electron microscopic observation of the sections incubated with anti-FLAP antibodies revealed that FLAP was strongly associated with the lumen of the nuclear envelope and endoplasmic reticulum of these cells (Fig. $1 B$ ). FLAP immunogold label was not observed along the plasma membrane, associated with any other membrane structures, or within the nucleus. In marked contrast to this distribution of FLAP, sections of resting AM incubated with anti-5-LO IgG demonstrated abundant gold label within the euchromatin region of the nucleus (Fig. $1 A$ ). Significantly, no label was found over condensed heterochromatin or within the nucleolus. In addition, no 5-LO label was observed associated with the nuclear envelope. A few gold particles were visualized over the endoplasmic reticulum. Sections of resting AM incubated with either anti-FLAP or anti-5-LO IgG did not display any label associated with the Golgi complex, mitochondria, membrane-bound granules, or within the cytoplasmic ground substance. Even though the observed number, size, and amount of pigmented material contained within cytoplasmic inclusion bodies were very heterogeneous, and most likely reflect the widely varying lengths of time individual macrophages had been resident in alveoli, these patterns of immunogold labeling for FLAP and 5-LO in resting AM were observed consistently in all cells obtained from three separate donors.

The specificity of our immunolabeling procedure was demonstrated by blocking experiments in which the primary antibodies were preincubated with the appropriate free antigen before incubation with cryosections of resting AM. Blocking with free antigen eliminated virtually all of the immunogold-labeled 5-LO (Fig. $1 C$ ) and FLAP (Fig. 1 D). As an additional blocking control, anti-FLAP IgG was preincubated with excess quantities of a peptide corresponding to FLAP amino acid residues 101-118, which shares no sequence homology with the immunizing peptide (FLAP amino acid residues 41-52), before immunolabeling. This peptide had no effect on anti-FLAP labeling in our experiments (data not shown).

We wished to use a complementary approach to confirm the immunoelectron microscopic observation that resting human AM contain abundant 5-LO within the nucleus. Therefore, freshly isolated AM were disrupted by hypotonic swelling and Dounce homogenization and fractionated into crude nuclear, cytosolic, and membrane fractions by differential centrifugation. Aliquots of fractions containing equal amounts of protein $(\sim 20 \mu \mathrm{g})$ were then subjected to immunoblot analysis for 5LO, with parallel analysis for FLAP or LTA $_{4}$ hydrolase (the enzyme responsible for catalyzing the proximate synthesis of $\mathrm{LTB}_{4}$ ) as markers of the nucleus/endoplasmic reticulum or cytosol (25), respectively. As shown in Fig. $2 A$, FLAP was present in both nuclear and membrane fractions, and $\mathrm{LTA}_{4}$ hydrolase was predominantly in the cytosol fraction, as expected; these data validate the fractionation procedure used. Importantly, substantial quantities of immunoreactive 5-LO were present in the nuclear fraction of human AM, as well as in the other two compartments. We have reported previously that resting resident rat AM also demonstrate a large amount of 5-LO in the particulate fraction, in contrast with autologous resident peritoneal macrophages (19); however, the cell disruption and fractionation techniques used in that study were not designed to optimize the integrity or recovery of cell nuclei. We therefore extended the present methods used for human cells to freshly isolated resting rat AM. As shown in Fig. $2 B$, substantial 


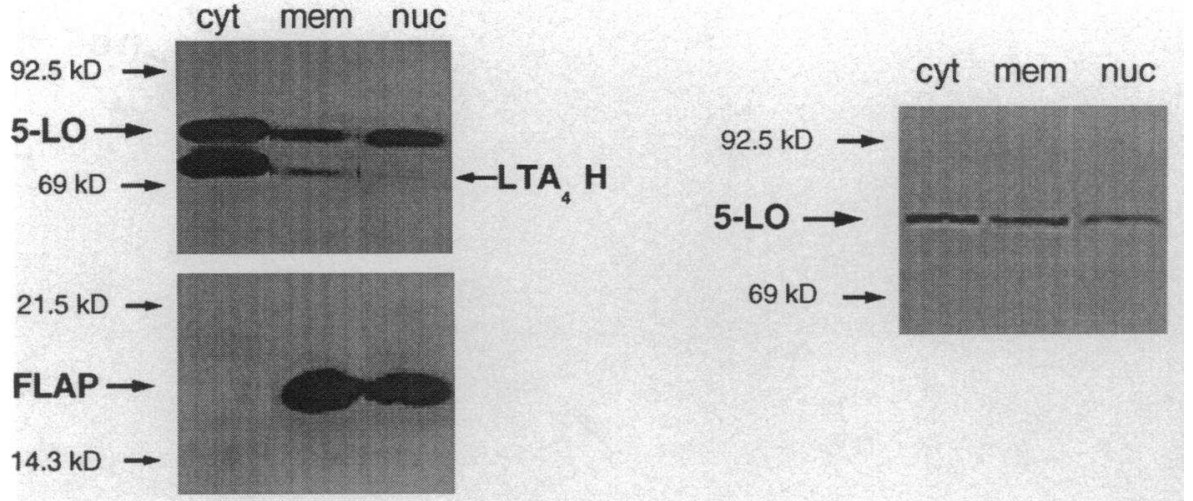

Figure 2. Immunoblot analysis of 5-LO and FLAP in resting AM. Freshly isolated human $(A)$ and rat $(B)$ AM were disrupted by Dounce homogenization and fractionated into cytosol (cyt), membrane (mem), and nuclear ( $n u c$ ) fractions. Equal amounts of protein $(\sim 20 \mu \mathrm{g})$ from each fraction were subjected to SDS-PAGE on 10\% (5-LO and $\mathrm{LTA}_{4}$ hydrolase) or $15 \%$ (FLAP) gels, followed by electrotransfer and immunoblotting. The bands corresponding to 5-LO (78 kD), LTA hydrolase (68 kD), and FLAP $(18 \mathrm{kD})$ are indicated. Migration of molecular weight markers is indicated. quantities of 5-LO were similarly present in the nuclear fraction of rat AM; as with human AM, the other two fractions also contained significant amounts of 5-LO protein. These data confirm our electron microscopic localization studies and clearly demonstrate that resting AM derived from both humans and rats contain a large pool of 5-LO within the nucleus. These immunoblot results are also of interest in that they demonstrate a soluble, presumably cytosolic, pool of enzyme in AM which was not evident by electron microscopy.

Although electron microscopy identified 5-LO in the euchromatin region of the nucleus in all sections of resting AM examined, this technique is limited in that, relative to fractionation experiments, only a small number of cells can be examined. We therefore used indirect immunofluorescence microscopy of Cytospin preparations to investigate 5-LO localization in a larger number of human AM. As shown in Fig. $3 A$, bright intranuclear fluorescence distributed in a mottled pattern, consistent with its localization in the euchromatin, was the characteristic feature of resting AM preparations incubated with anti-5-LO IgG followed by rhodamine-conjugated secondary antibody. Very little, if any, fluorescent label could be detected in the cytoplasm of these cells. Specificity of the anti-5-LO antiserum was demonstrated in Fig. $3 C$ where nonimmune serum, used as the primary antibody probe, failed to label any cells.

To determine the effect of activation on the intracellular distribution of FLAP and 5-LO, freshly isolated AM were incubated with the calcium ionophore A23187 before fixation, freezing, cryosectioning, and immunolabeling. Activation of the 5LO metabolic pathway in these same cell suspensions was documented by measuring levels of immunoreactive $\mathrm{LTB}_{4}$ in their cell-free supernatants. Calcium ionophore stimulation resulted in 8-12-fold increases in $\mathrm{LTB}_{4}$ synthesis over the levels elaborated by unstimulated control cells from both populations (data not shown ).

Examination of immunogold labeled sections demonstrated that, in marked contrast to resting cells, ionophore-activated AM displayed intense anti-5-LO immunolabeling of the inner membrane of the nuclear envelope (Fig. $4 B$ ); importantly, there was no labeling of the plasma membrane (Fig. $4 A$ ). In addition, the label previously observed in the euchromatin region of the nucleus of resting cells was significantly diminished after activation. These two observations are consistent with the conclusion that, after ionophore stimulation of AM, 5-LO translocates from the euchromatin region of the nucleus to the nuclear envelope. As in resting AM, sections of activated cells incubated with anti-FLAP antibody displayed immunogold labeling of the lumen of the nuclear envelope and the endoplasmic reticulum (Fig. $4 \mathrm{C}$ ). 5-LO was also occasionally observed
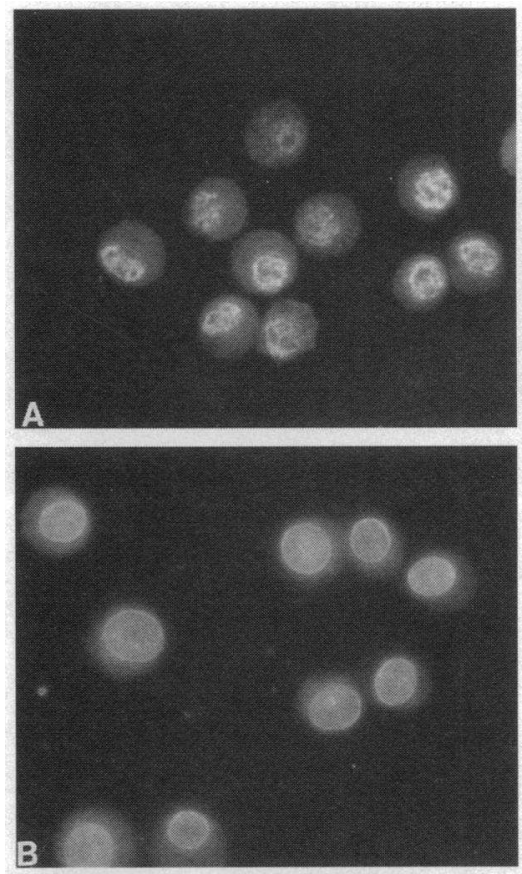

Figure 3. Indirect immunofluorescence microscopic detection of 5-LO in resting $(A$ and $C)$ and activated $(B)$ human

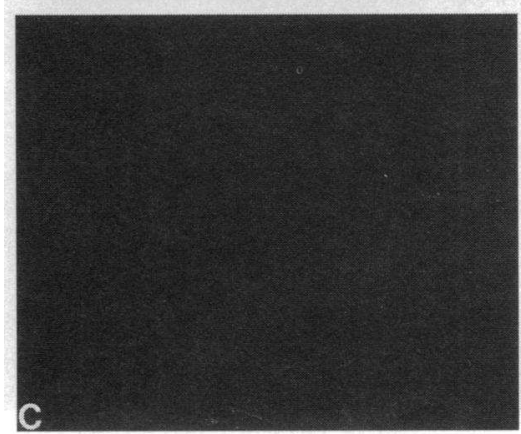
AM. Cytospin preparations of freshly isolated human AM were fixed, permeabilized, and incubated with either anti-5LO antiserum ( $A$ and $B)$ or nonimmune serum $(C)$, followed by rhodamine-conjugated secondary IgG. Cells were examined at a magnification of 40 . 

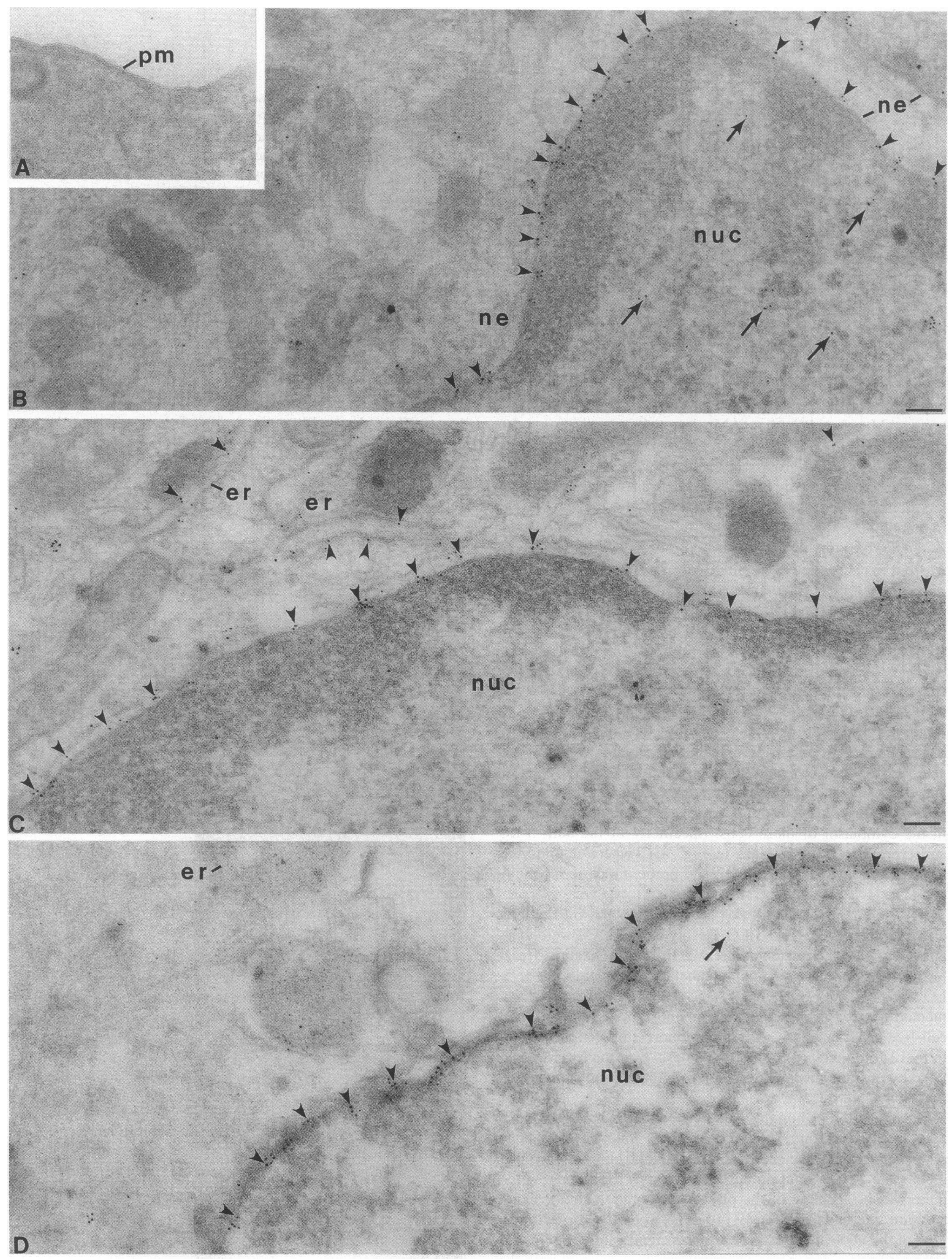
Table I. Quantitation of 5-LO Distribution in Resting, Activated, and $M K-886-$ treated Activated AM

\begin{tabular}{lccc}
\hline & Control & A23187 & $\begin{array}{c}\text { A23187+ } \\
\text { MK-886 }\end{array}$ \\
\hline $\begin{array}{c}\text { Nuclear envelope } \\
(\text { Au particles } / \mu \mathrm{m})\end{array}$ & $2.12 \pm 0.7^{* \pm}$ & $20.5 \pm 4.7$ & $17.3 \pm 6.1$ \\
$\begin{array}{c}\text { Nucleoplasm } \\
\left(\text { Au particles } / \mu \mathrm{m}^{2}\right)\end{array}$ & $23.9 \pm 9.6^{* \ddagger}$ & $3.26 \pm 1.8$ & $1.43 \pm 0.6$ \\
$\begin{array}{c}\text { Percent envelope-associated } \\
(\text { envelope/total) }\end{array}$ & 8.1 & 86.3 & 92.4 \\
\hline
\end{tabular}

AM were incubated for $5 \mathrm{~min}$ with and without $\mathrm{A} 23187$ before fixation, freezing, sectioning, and immunolabeling with anti-5-LO IgG. Separate batches of cells were also incubated with MK- 886 for 5 min before addition of A23187. The number of gold particles within 1 diameter of the nuclear envelope was then counted and the length of the nuclear envelope was measured. Also, the number of gold particles over the nucleoplasm was counted and the nuclear area was measured. The number of particles per length or area was then calculated. At least 8 separate micrographs, each including at least $10 \mu \mathrm{m}$ of nuclear envelope and 8 $\mu \mathrm{m}^{2}$ of nuclear area, were evaluated for each calculation. These data were calculated from a pool of observations taken from three independent preparations of fixed cells. * Different from A23187-treated, $P$ $\ll 0.001$ by Student's $t$ test; ${ }^{\ddagger}$ different from A23187/MK-886-treated, $P \ll 0.001$ by Student's $t$ test.

associated with the endoplasmic reticulum. As was the case with resting cells, neither antibody yielded any significant labeling of the plasma membrane, Golgi complex, mitochondria, membrane-bound granules, or cytoplasmic ground substance. In addition, with either probe there was very little background label observed outside of the cells. In an attempt to quantify the translocation of 5-LO from the euchromatin region to the nuclear envelope, we counted the number of gold particles associated with both structures in resting as well as activated AM. The results, presented in Table I, demonstrate a correlation between the decrease of label in the euchromatin and the increase of label along the nuclear envelope.

To corroborate and extend these electronmicroscopic observations on activated human AM, we performed both immunoblot analysis and immunofluorescence microscopy. As shown in Fig. $5 \mathrm{~A}$, ionophore stimulation had no effect on the distribution of 5-LO among the three subcellular fractions examined. This is precisely what would be expected if intranuclear 5-LO were redistributed to the nuclear envelope. This was further confirmed by immunofluorescence microscopy (Fig. $3 B$ ) which revealed a ring of 5-LO fluorescence outlining the nucleus of activated cells which was clearly distinct from the mottled, euchromatin pattern seen in resting AM (Fig. 3 A). It should also be noted that both immunoblot and immunofluorescence analysis disclosed no loss of cytosolic 5-LO upon A23187 activation of $A M$ and that this confirms the suggestion from Table I that all of the 5-LO which translocated to the nuclear envelope of AM originated from within the nucleus.

Subcellular localization of 5-LO and FLAP in PBL. Experiments identical to those presented above were carried out in parallel on autologous PBL. As described previously (12), in resting PBL FLAP was observed to be concentrated in the lumen of the nuclear envelope and in the endoplasmic reticulum (Fig. $6 \mathrm{~A}$ ). Also in agreement with earlier results, the intensity of 5LO labeling in resting PBL was very low; however, the little label that was observed was invariably associated with the euchromatin region of the nucleus (Fig. $6 B$ ). No differences in the localization of either protein could be discerned between the PMN and PBM comprising the PBL population. PBM and PMN were also separately disrupted, fractionated, and subjected to immunoblot analysis using the same techniques as were applied to AM. As shown in Fig. 5, 5-LO was contained predominantly in the cytosol fraction of both PBM (Fig. 5 B) and PMN (Fig. $5 C$ ), with much smaller quantities in the membrane and nuclear fraction. These data thus confirm the electron microscopic finding that the relative abundance of 5-LO within the nucleus of AM exceeds that present in PBL. They also demonstrate the predominant cytosolic pool of 5-LO which was not apparent in PBL by electron microscopy.

Ionophore stimulation of PBL was also carried out. This resulted in a several hundred-fold increase in the production of $\mathrm{LTB}_{4}$ (data not shown), confirming activation of the 5-LO pathway. As reported previously (12), the localization of FLAP and 5-LO in activated PBL was very similar to that observed in activated AM, with both proteins strongly associated with the nuclear envelope (Fig. 7); this was true for both PMN and PBM. Interestingly, we observed relatively more 5-LO label compared with FLAP in the nuclear envelope of activated AM, whereas this relationship was reversed in activated PBL, in which there was always relatively more FLAP label compared with 5-LO. Immunoblot analysis of stimulated PBM (Fig. 5 B) and PMN (Fig. $5 C$ ) confirmed that the nuclear fraction was the only fraction exhibiting an increase in 5-LO concomitant with its loss from the cytosol fraction.

Effect of MK-886 on translocation of 5-LO in activated AM and PBL. To determine if FLAP plays a role in mediating the translocation of 5-LO to the nuclear envelope, AM and PBL were preincubated with the FLAP inhibitor MK-886 or its inactive analogue L-583,916, and coincubated with these agents during ionophore activation. As expected, MK-886 treatment resulted in $>95 \%$ inhibition of stimulated $\mathrm{LTB}_{4}$ synthesis in both cell types whereas the inactive analogue, L-583,916, had a minimal effect (data not shown). Despite its inhibition of 5-

Figure 4. Immunogold labeling of ionophore-activated AM incubated with anti-5-LO IgG $(A, B$, and $D)$ or anti-FLAP IgG $(C)$. The section shown in $D$ was derived from cells coincubated with the FLAP binding inhibitor, MK-886, along with A23187. Immunolabeled 5-LO is concentrated along the inner membrane of the nuclear envelope (arrowheads), and compared with resting AM is significantly depleted from the euchromatin region of the nucleus $(B)$. Note that only a few scattered gold particles (arrows) can be seen in the euchromatin region of the nucleus of this activated cell. Also notice that no gold particles are found along the plasma membrane $(p m, A)$. As is the case in both resting AM (Fig. $1 B$ ) and resting PBL (Fig. $6 \mathrm{~A}$ ), FLAP is observed along the nuclear envelope and endoplasmic reticulum $(C)$. MK-886 treatment of activated cells, which completely blocked the synthesis of $\mathrm{LTB}_{4}$, had no effect on the distribution of 5-LO $(D)$; immunogold-labeled 5-LO is observed along the inner membrane of the nuclear envelope (arrowheads) in a pattern which is indistinguishable from that obtained in the absence of MK- 886 and is only rarely found within the nucleus (nuc, arrows). Bar, $100 \mathrm{~nm}$. 


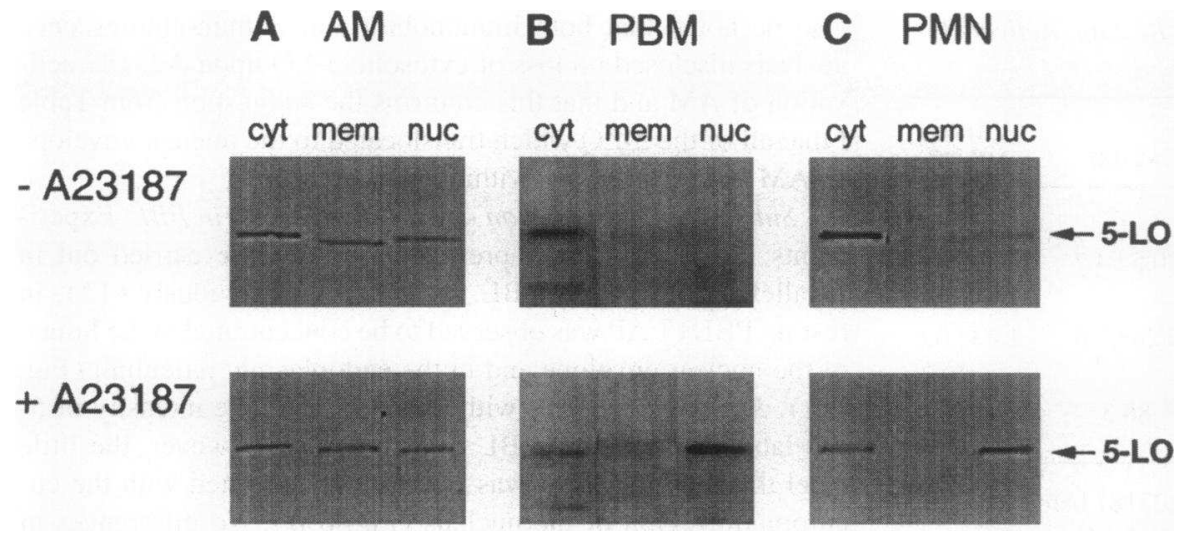

Figure 5. Immunoblot analysis of 5-LO in subcellular fractions of resting and activated cells. Human AM $(A)$, PBM $(B)$, and PMN $(C)$ were incubated with or without A23187, after which they were disrupted, fractionated, and fractions subjected to SDS-PAGE and immunoblot detection of 5-LO.
LO metabolism in both cell types, MK-886 had no effect on the translocation of 5-LO to the nuclear envelope in either type. 5-LO immunogold labeling of AM incubated with MK-886 plus A23187 displayed a pattern that was identical to that obtained in cells incubated with A23187 alone (Fig. $4 C$ ); i.e., 5-LO was concentrated along the nuclear envelope and was barely detectable in the euchromatin region. Table I presents quantitative data on 5-LO distribution in activated AM treated with MK886. Similar results were obtained with activated PBL (data not shown). The inactive compound L-583,916 also had no effect on the observed distribution of immunolabeled 5-LO in activated cells (data not shown).

\section{Discussion}

In this study, we have used a variety of techniques to characterize the subcellular localization of 5-LO and FLAP in human
$\mathrm{AM}$ as well as autologous PBL. Our analysis of human AM provides the first immunolocalization data reported for this particular cell type, which is thought to represent the major cellular source of 5-LO products present in the normal lung. As reported previously for PBL (12) (and confirmed herein in autologous PBL obtained from the same donors), FLAP was localized to the nuclear envelope in both resting and activated AM. However, the localization of 5-LO in resting AM contrasted markedly with that observed in PBL. Whereas 5-LO was predominantly cytosolic in resting PBL, large amounts of 5-LO were visualized in the euchromatin region of the nucleus of resting AM. 5-LO was detected in abundance in the nuclear envelope, but not on the other cellular membranes, of ionophore-activated PBL as well as AM. In AM, activation resulted in the nearly complete redistribution of 5-LO from the euchromatin to the nuclear envelope. We have also, for the first time, demonstrated the effects of the FLAP inhibitor MK-886 on the immunolocali-
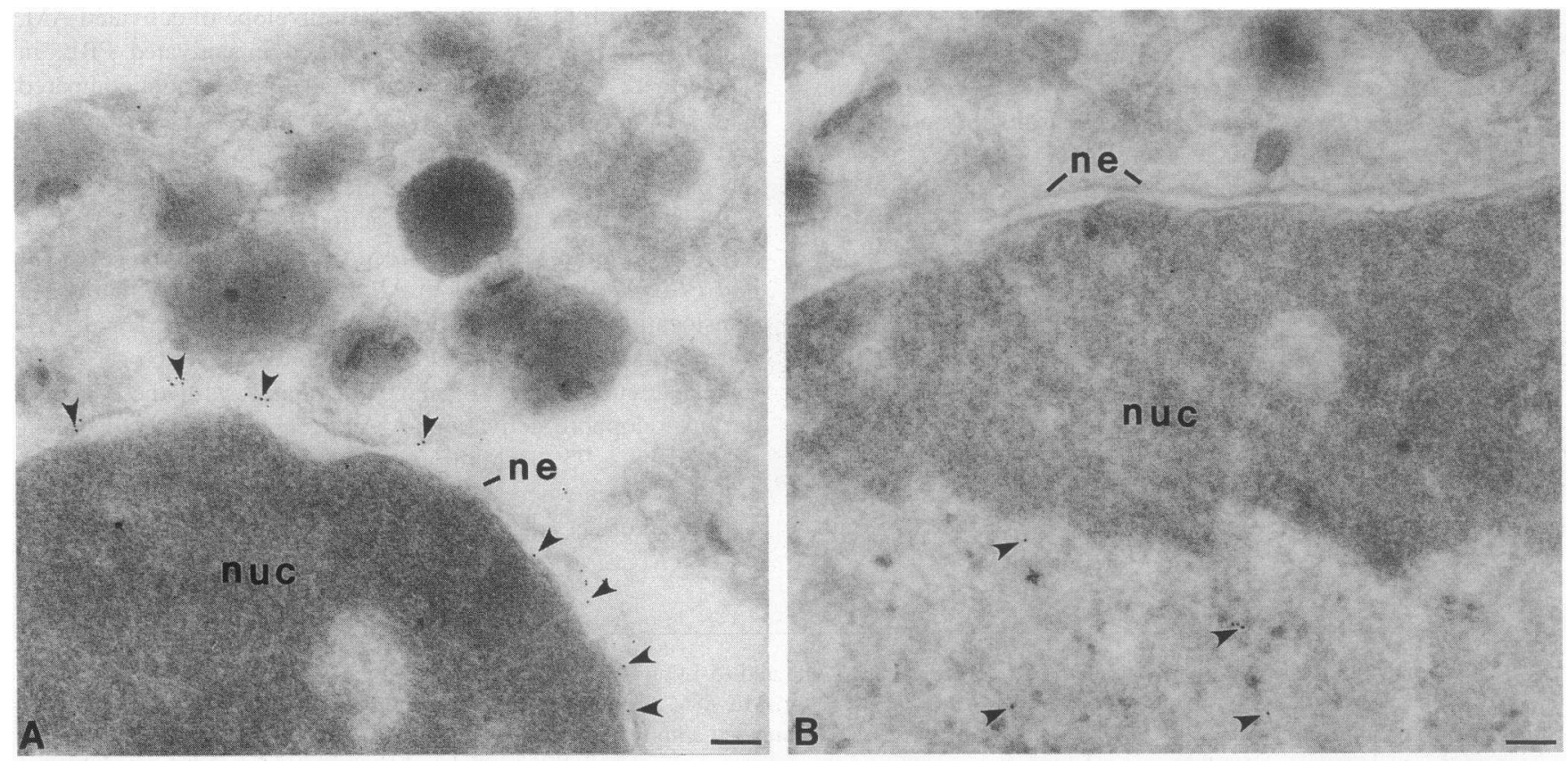

Figure 6. Immunogold labeling of sections of autologous, resting PBL incubated with anti-FLAP IgG (A) or anti-5-LO IgG (B). As in AM (Fig. 1), FLAP immunogold label (arrowheads) is associated primarily with the nuclear envelope ( $n e$ ). Unlike AM (Fig. 1), sections of resting PBL incubated with anti-5-LO display only a small number of gold particles (arrowheads) scattered throughout the euchromatin region of the nucleus $(n u c)$. No 5-LO labeling is observed associated with the nuclear envelope ( $n e$ ), the endoplasmic reticulum, or with any other location. Bar, 100 nm. 

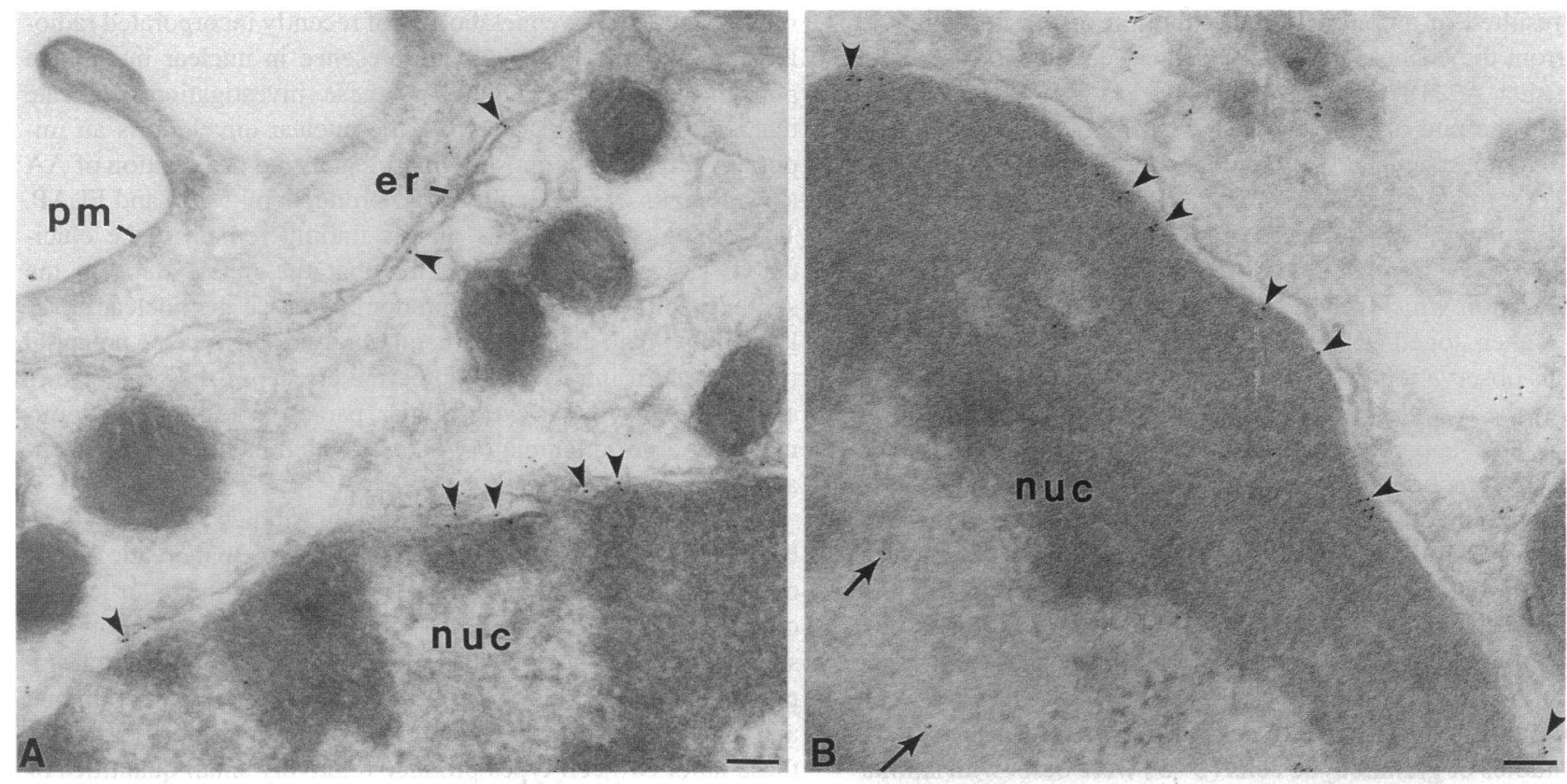

Figure 7. Immunogold labeling of autologous, ionophore-activated PBL incubated with anti-FLAP IgG $(A)$ or anti-5-LO IgG (B). The nuclear envelope is heavily immunolabeled in sections incubated with anti-FLAP IgG ( $A$, arrowheads). The nuclear envelope is also immunolabeled in sections incubated with anti-5-LO IgG ( $B$, arrowheads). In this example, both antibodies also label the endoplasmic reticulum (er, arrowheads). There are also a few gold particles observed within the euchromatin region of the nucleus (nuc, arrows) on sections labeled with anti-5-LO IgG (B). Bar, $100 \mathrm{~nm}$.

zation of 5-LO in intact cells. Despite completely inhibiting $\mathrm{LTB}_{4}$ synthesis by both AM and PBL, MK-886 failed to prevent translocation of 5-LO to the nuclear envelope.

In this manuscript we have used immunogold labeling on ultrathin frozen sections, fluorescent immunolocalization on whole cells, and subcellular fractionation/immunoblot analysis to elucidate the intracellular distribution of 5-LO and FLAP in resting and activated cells. Each of these techniques has intrinsic advantages as well as certain disadvantages. Immunogold labeling of ultrathin frozen sections has the advantage of resolution on the scale of intracellular membrane compartments. In addition, since accessibility of the intracellular compartments is obtained by virtue of the fact that the membrane compartments are cut open, antibody probes have ready access to epitopes on either side of any intracellular membrane. However, the concomitant possibility that soluble components may leak out of the section and be washed away is an unavoidable disadvantage of this technique. It is for this reason that immunoelectron microscopy is often not suitable for visualizing soluble cytoplasmic constituents, and this is likely the reason that 5-LO was not visualized by this technique in resting blood leukocytes in either this or previous (12) studies. It is precisely because of this limitation that we complemented the immunogold observations with data derived from fractionation/immunoblot and immunofluorescence analyses. Immunofluorescence microscopy has the advantage that significantly larger numbers of cells can be observed than is possible with electronmicroscopic techniques, thus mitigating potential sampling errors. In addition, this technique is capable of detecting cytoplasmic 5-LO. However, it too tends to underestimate soluble pools of 5-LO (and other proteins ) because, although cells have not been sectioned, they must be permeabilized for antibody to penetrate the plasma membrane. Subcellular fractionation followed by immunoblot analysis is not subject to the same potential loss of soluble components as the two preceding techniques, but rather, has its own limitations. In particular, even relatively gentle methods of cell disruption result in a small proportion of ruptured nuclei. As a result, the postnuclear fractions of these homogenates will be contaminated with small amounts of 5-LO derived from ruptured nuclei. In addition, it is also possible that components which are freely soluble in the living cell may stick to various particulate components after cell disruption. Therefore, it can be seen that each technique has its own advantages and disadvantages, and by combining all three approaches it is possible to gain a far more complete picture of the processes involved in trafficking of 5-LO and FLAP than could be inferred from any single approach.

We have reported previously that, in resting rat AM disrupted by sonication, a substantial proportion of 5-LO immunoreactivity (and enzyme activity) was found in the $100,000 \mathrm{~g}$ pellet fraction (19). This contrasts with the situation in rat peritoneal macrophages and human PMN, in which 5-LO was essentially limited to the $100,000 \mathrm{~g}$ supernatant (19). The presence of 5-LO in a high-speed pellet has been observed similarly in resting human AM, in contrast with human PBM where it was restricted to the high-speed supernatant (18). Interestingly, in previous work we were unable to demonstrate any additional redistribution of 5-LO to the particulate fraction after ionophore activation of rat AM (19). The subcellular localization studies described in this report extend and help to explain these earlier biochemical data. The most striking feature of our current findings was the intense 5-LO labeling of the euchromatin region of the nucleus of resting AM. The specificity of this labeling was documented by the use of immune serum which had been preadsorbed with purified recombinant human 5-LO and was also demonstrated by the observation that brief ionophore treat- 
ment resulted in a complete redistribution of the immunogold label from the euchromatin to the nuclear envelope. The observation that $\mathrm{A} 23187$ treatment also leads to an 8-12-fold increase in the rate of synthesis of LTB $_{4}$ implies that these cells were in a quiescent state before exposure to ionophore and that ionophore treatment leads to $\mathrm{Ca}^{2+}$-dependent cell activation with the concomitant synthesis of $\mathrm{LTB}_{4}$. Thus, the euchromatin labeling observed in resting AM could not be a result of in situ cell activation which might have occurred before cell procurement. Taken together, these results strongly suggest that the previous observation of 5-LO in high-speed pellet fractions (18, 19) was the result of the euchromatin distribution of 5-LO.

It is now apparent that the experimental methods used in earlier AM fractionation studies $(19,26)$ were not well-suited to recognize the important role of the nucleus in the biology of 5-LO activation. First, sonication, a relatively harsh method of cell disruption, was used, which would be expected to result in some degree of nuclear disruption. Second, since in those studies the low-speed pellet was discarded before ultracentrifugation, any nuclei remaining intact would have likewise been discarded. It is appropriate to acknowledge that early fractionation studies of granulocytic cells (3-5) were beset with similar limitations. However, it is possible to reexamine those early data in light of the present ultrastructural findings. The highspeed particulate fraction obtained in those studies undoubtedly contained disrupted nuclear material; the presence of similar amounts of 5-LO in that fraction obtained from both resting and activated AM would be expected if 5-LO were redistributing within the nucleus from the euchromatin to the nuclear envelope. With the application of a gentler method of cell disruption and nuclear isolation via low-speed centrifugation, we have indeed confirmed by immunoblot analysis that resting AM derived from both humans and rats contain an intranuclear pool of 5-LO which is substantially greater than that found in PBM (Fig. 5) or in rat peritoneal macrophages (27). However, immunoreactive 5-LO was also recognized in other subcellular compartments within AM; the functional significance of these discrete enzyme pools remains to be investigated.

AM represent a heterogeneous population of long-lived cells which have emigrated to the alveolar space at different times (13). This heterogeneity was recognized in ultrathin sections of AM by qualitative and quantitative variations in phagolysosomes. Nonetheless, the localization of 5-LO to the euchromatin was observed in all AM sections examined. In this regard, immunofluorescent microscopic examination of human AM extended the information available from electron microscopy by demonstrating that intense nuclear fluorescence for 5-LO was a ubiquitous characteristic of these cells.

The present results also extend to the AM two observations made previously for PBL (12) regarding FLAP. First, FLAP was present predominantly in the nuclear envelope and, to a lesser extent, in the endoplasmic reticulum. Second, FLAP localization was unaffected by cell stimulation with concomitant $\mathrm{LTB}_{4}$ synthesis. Thus, in all cells studied to date, including human PBL, human AM, and rat peritoneal macrophages (27), FLAP appears to be constitutively and permanently localized predominantly to the nucleus, and, more specifically, to the nuclear envelope. Interestingly, high molecular mass arachidonoyl-selective cytosolic phospholipase $\mathrm{A}_{2}$ has also been demonstrated to redistribute to the nuclear fraction with activation (27). This latter finding is consistent with the previous observation (28) in mouse fibrosarcoma cells that the capacity for release and oxidative metabolism of recently incorporated radiolabeled AA correlated with its presence in nuclear membrane phospholipids. Taken together, these investigations indicate that, in a variety of cell types, the nuclear envelope is an important site for both phospholipase-catalyzed deacylation of AA as well as its conversion to 5-LO products by 5-LO and FLAP. The biologic implications of this finding remain to be elucidated. However, the recognition that the initial steps in the synthesis of LT likely occur predominantly at the nuclear envelope, rather than the plasma membrane, emphasizes the potential importance of intracellular autocrine effects of these mediators as opposed to those extracellular paracrine effects, predominantly of a proinflammatory nature, which have been traditionally appreciated.

Ultrastructural immunolocalization studies of 5-LO have been reported in two other cell types. Porcine pancreatic acinar cells were demonstrated to contain 5-LO along the inner leaflets of the nuclear membrane (29), and human corpus luteum was shown to contain 5-LO in a variety of sites, including cytoplasm, plasma membrane, endoplasmic reticulum, nuclear membrane, and nuclear heterochromatin, but not euchromatin (30). As these latter two cell types produce relatively small quantities of LT compared with leukocytes, and the effects of cell activation were not examined, the functional significance of these findings is not clear. Moreover, 5-LO was not found in the euchromatin of these cell types. Nonetheless, the detection of 5-LO in the nucleus of these cells is of interest in the context of the present findings.

The LT synthesis inhibitor MK-886 binds to FLAP (6). Since this drug and others which share this same property have been demonstrated in a number of studies $(7,9,19,31)$ to prevent redistribution of 5-LO to the particulate fraction of disrupted cells, it was suggested originally that FLAP might serve as a membrane docking protein for the translocated enzyme. However, it has not been possible to demonstrate a direct interaction between FLAP and 5-LO (31). More importantly, a dissociation between membrane association of 5-LO and the presence of FLAP was observed (32) in osteosarcoma cells transfected with the cDNA for 5-LO only. In these experiments, ionophore stimulation resulted in 5-LO redistribution to the particulate fraction despite the absence of FLAP; however, LT synthesis did not occur. These data suggested that membrane association of 5-LO and its enzymatic activation were two separable events. Our results provide the first immunolocalization studies investigating the effects of MK-886 on 5-LO translocation and clearly demonstrated that, although the drug almost completely inhibited $\mathrm{LTB}_{4}$ synthesis, it had no effect on the translocation of 5-LO to the nuclear envelope in either AM or PBL. These data demonstrate conclusively that FLAP is not involved directly in the translocation of 5-LO and suggest that the earlier results $(7,9,19,31)$ obtained using harshly disrupted cells were misinterpreted. Inasmuch as FLAP inhibitors are under clinical development for the treatment of various inflammatory conditions, this mechanistic information is of great significance. The data also indicate that, while the association of 5-LO with the nuclear envelope may be necessary for LT synthesis, it is not sufficient for LT synthesis, consistent with the two-step model suggested previously $(19,32)$. Synthesis of these lipid mediators thus requires that 5-LO both associate with the nuclear envelope as well as interact with FLAP. Although the precise role of FLAP in LT synthesis therefore remains to be determined, recent studies (33) indicating that it is an AA- 
binding protein suggest that it may be involved in the presentation to 5-LO of AA liberated by phospholipase.

Our finding that 5-LO is distributed throughout the euchromatin of resting AM poses several intriguing questions. In particular, what factor in the pulmonary milieu is responsible for the dramatic and consistent change in subcellular localization of 5-LO which accompanies the migration of PBM into the alveolar space? Since the human tracheobronchial tree is colonized with bacteria, AM may be exposed to endotoxin in situ. Thus, exposure to endotoxin could potentially be responsible for the intranuclear localization of 5-LO in AM. Indeed, this possibility would be extremely difficult to rule out directly in humans. However, there are several reasons to presume that endotoxin is not responsible for the intranuclear distribution of 5-LO. First is our immunoblot (Fig. $2 \mathrm{~B}$ ), demonstrating that a significant portion of the total cellular 5-LO is associated with the nuclear fraction even in resting AM obtained from rats housed in a pathogen-free environment. Second, we have reported recently that a similar nuclear distribution of 5-LO is found in unstimulated rat basophilic leukemia cells grown under sterile culture conditions (34). In at least these two cases, it is unlikely that endotoxin contamination is responsible for the intranuclear distribution of 5-LO. In addition to endotoxin, there are other features of the alveolar milieu (e.g., surfactant) which distinguish it from the bloodstream and which could account for the unusual distribution of 5-LO observed in AM. Indeed, the mere fact that AM had to transit across two cell layers and accompanying basement membranes to reach the alveolar space may have resulted in signals which led to the observed nuclear distribution. Identifying the particular features which might be responsible will be the subject of further investigation.

There are other interesting questions posed by our observations. First, how universal is the euchromatin distribution of 5LO observed in resting AM? This particular question is relevant in view of the weak euchromatin labeling observed in PBL (12) and the findings in pancreatic acinar cells (29) and corpora lutea (30). Furthermore, a number of proteins subsequently determined to be nuclear by immunolocalization studies were originally thought to be soluble on the basis of biochemical techniques $(35,36)$, acknowledging the propensity for homogenization and fractionation techniques to compromise nuclear integrity. We therefore cannot exclude the possibility that 5-LO might be at least partially localized within the nucleus of all cells. Second, since 5-LO does not contain typical nuclear localization sequences nor is it known to be posttranslationally modified $(37,38)$, what directs the protein into the nucleus of cells containing nuclear 5-LO? Finally, what biological functions might be served by 5-LO within the nucleus of such a cell? Its localization to the euchromatin region, the site of transcriptionally active chromatin, suggests a possible role of the enzyme or its products in regulating gene expression in cells such as the AM. These questions remain to be addressed in future investigations. The last question posed is of especial significance inasmuch as inhibition of 5-LO represents a promising antiinflammatory treatment strategy currently being investigated for application to a variety of human diseases.

\section{Acknowledgments}

The authors would like to thank Dr. Jilly Evans and Dr. Philip Vickers for generously providing the anti-5-LO, -FLAP, and -LTA $\mathrm{L}_{4}$ hydrolase antisera, MK-886, L-583,916, and FLAP peptides; Dr. Denis Riendeau for providing recombinant 5-LO; Robert McNish for technical assistance; Dr. Robert Paine for assistance with immunofluorescence microscopy; and Dr. Alan Williamson for support and encouragement.

This work was supported by Merck Research Laboratories and by grants from the National Heart, Lung, and Blood Institute (RO1-HL471 and Specialized Center of Research P50-HL46487). Michael J. Coffey is the recipient of National Institutes of Health Clinical Investigator Development Award HL-02810, and Marc Peters-Golden is the recipient of a Career Investigator Award from the American Lung Association. Thomas G. Brock is supported by a National Institutes of Health Institutional Training Grant (T32 HL-07749).

\section{References}

1. Lewis, R., K. Austen, and R. Soberman. 1990. Leukotrienes and other products of the 5-lipoxygenase pathway: biochemistry and relation to pathobiology in human disease. N. Engl. J. Med. 323:645-655.

2. Samuelsson, B., and C. D. Funk. 1989. Enzymes involved in the biosynthesis of leukotriene $B_{4}$. J. Biol. Chem. 264:19469-19472.

3. Wong, A., S. M. Hwang, M. N. Cook, G. K. Hogaboom, and S. T. Crooke. 1988. Interactions of 5-lipoxygenase with membranes: studies on the association of soluble enzyme with membranes and alterations in enzyme activity. Biochemistry. 27:6763-6769.

4. Rouzer, C. A., and S. Kargman. 1988. Translocation of 5-lipoxygenase to the membrane in human leukocytes challenged with ionophore A23187. J. Biol. Chem. 263:10980-10988.

5. Kargman, S., and C. A. Rouzer. 1989. Studies on the regulation, biosynthesis, and activation of 5-lipoxygenase in differentiated HL60 cells. J. Biol. Chem. 264:13313-13320.

6. Miller, D. K., J. W. Gillard, P. J. Vickers, S. Sadowski, C. Leveille, J. A. Mancini, P. Charleson, R. A. F. Dixon, A. W. Ford-Hutchinson, R. Fortin, et al. 1990. Identification and isolation of a membrane protein necessary for leukotriene production. Nature (Lond.). 343:278-281.

7. Rouzer, C. A., A. W. Ford-Hutchinson, H. E. Morton, and J. W. Gillard 1990. MK886, a potent and specific leukotriene biosynthesis inhibitor blocks and reverses the membrane association of 5-lipoxygenase in ionophore-challenged leukocytes. J. Biol. Chem. 265:1436-1442.

8. Charleson, S., P. Prasit, S. Leger, J. Gillard, P. Vickers, J. Mancini, P. Charleson, J. Guay, A. Ford-Hutchinson, and J. Evans. 1992. Characterization of a 5-lipoxygenase-activating protein binding assay: correlation of affinity for 5lipoxygenase-activating protein with leukotriene synthesis inhibition. Mol. Pharmacol. 41:873-879.

9. Hatzelmann, A., R. Fruchtmann, K. Mohrs, S. Raddatz, and R. MullerPeddinghaus. 1993. Mode of action of the new selective leukotriene synthesis inhibitor BAY X 1005 \{(R)-2-[4-(quinolin-2-yl-methoxy)phenyl]-2-cyclopentyl acetic acid $\}$ and structurally related compounds. Biochem. Pharmacol. 45:101-111.

10. Dixon, R. A. F., R. E. Diehl, E. Opas, E. Rands, P. J. Vickers, J. F. Evans, J. W. Gillard, and D. K. Miller. 1990. Requirement of a 5-lipoxygenase-activating protein for leukotriene synthesis. Nature (Lond.). 343:282-284.

11. Ford-Hutchinson, A. 1991. FLAP: a novel drug target for inhibiting the synthesis of leukotrienes. Trends Pharmacol. Sci. 12:68-70.

12. Woods, J. W., J. F. Evans, D. Ethier, S. Scott, P. J. Vickers, L. Hearn, J. A. Heibein, S. Charleson, and I. I. Singer. 1993. 5-Lipoxygenase and 5-lipoxygenase-activating protein are localized in the nuclear envelope of activated human leukocytes. J. Exp. Med. 178:1935-1946.

13. Fels, A., and Z. Cohn. 1986. The alveolar macrophage. J. Appl. Physiol. 60:353-369.

14. Peters-Golden, M., R. W. McNish, R. Hyzy, C. Shelly, and G. B. Toews. 1990. Alterations in the pattern of arachidonate metabolism accompany rat macrophage differentiation in the lung. J. Immunol. 144:263-270.

15. Balter, M., G. Toews, and M. Peters-Golden. 1989. Different patterns of arachidonate metabolism in autologous human blood monocytes and alveolar macrophages. J. Immunol. 142:602-608.

16. Bigby, T., and M. Holtzman. 1987. Enhanced 5-lipoxygenase activity in lung macrophages compared to monocytes from normal subjects. J. Immunol. 138:1546-1550.

17. Pueringer, R., C. Bahns, and G. Hunninghake. 1992. Alveolar macrophages have greater amounts of the enzyme 5-lipoxygenase than do monocytes. J. Appl. Physiol. 73:781-786.

18. Coffey, M. J., S. E. Wilcoxen, and M. Peters-Golden. 1994. Increases in 5-lipoxygenase activating protein expression account for enhanced capacity for 5-lipoxygenase metabolism which accompanies differentiation of peripheral blood monocytes into alveolar macrophages. Am. J. Respir. Cell Mol. Biol. 11:153158.

19. Coffey, M., M. Peters-Golden, J. Fantone, and P. Sporn. 1992. Membrane 
association of active 5-lipoxygenase in resting cells: evidence for novel regulation of the enzyme in the rat alveolar macrophage. J. Biol. Chem. 267:570-576.

20. Vissers, M., S. Jester, and J. Fantone. 1988. Rapid purification of human peripheral blood monocytes by centrifugation through Ficoll-Hypaque and Sepracell-MN. J. Immunol. Methods. 110:203-207.

21. Login, G. R., and A. M. Dvorak. 1985. Microwave energy fixation for electron microscopy. Am. J. Pathol. 120:230-243.

22. McLean, I. W., and P. K. Nakane. 1974. Periodate-lysine-paraformaldehyde fixative. A new fixation for immunoelectron microscopy. J. Histochem. Cytochem. 22:1077-1083.

23. Tokuyasu, K. T. 1989. Use of poly (vinylpyrrolidone) and poly(vinyl alcohol) for cryoultramicrotomy. Histochem. J. 21:163-171.

24. Tokuyasu, K. T. 1986. Application of cryoultramicrotomy to immunocytochemistry. J. Microsc. (Oxf.). 143:139-149.

25. Evans, J. F., P. Dupuis, and A. W. Ford-Hutchinson. 1985. Purification and characterisation of leukotriene $\mathrm{A}_{4}$ hydrolase from rat neutrophils. Biochim. Biophys. Acta. 840:43-50.

26. Coffey, M., M. Gyetko, and M. Peters-Golden. 1993. 1,25-Dihydroxyvitamin $D_{3}$ upregulates 5-lipoxygenase metabolism and 5-lipoxygenase activating protein in peripheral blood monocytes as they differentiate into mature macrophages. J. Lipid Mediators. 6:43-51.

27. Peters-Golden, M., and R. McNish. 1993. Redistribution of 5-lipoxygenase and cytosolic phospholipase $A_{2}$ to the nuclear fraction upon macrophage activation. Biochem. Biophys. Res. Commun. 196:18-24.

28. Capriotti, A., E. Furth, M. Arrasmith, and M. Laposata. 1988. Arachidonate released upon agonist stimulation preferentially originates from arachidonate most recently incorporated into nuclear membrane phospholipids. J. Biol. Chem. 263:10029-10034.
29. Natsui, K., N. Ueda, S. Yamamoto, N. Komatsu, and K. Watanabe. 1991 Arachidonate 5-lipoxygenase of porcine pancreas: its localization in acinar cells. Biochim. Biophys. Acta. 1085:241-247.

30. Mitchell, D., Z. Lei, and C. Rao. 1991. The enzymes in cyclooxygenase and lipoxygenase pathways of arachidonic acid metabolism in human corpora lutea: dependence on luteal phase, cellular and subcellular distribution. Prostaglandins Leukotrienes Essent. Fatty Acids. 43:1-12.

31. Kargman, S., P. Prasit, and J. Evans. 1991. Translocation of HL-60 cell 5-lipoxygenase. J. Biol. Chem. 266:23745-23752.

32. Kargman, S., P. Vickers, and J. Evans. 1992. A23187-induced translocation of 5-lipoxygenase in osteosarcoma cells. J. Cell Biol. 119:1701-1709.

33. Mancini, J., M. Abramovitz, M. Cox, E. Wong, S. Charleson, H. Perrier, Z. Wang, P. Prasit, and P. Vickers. 1993. 5-lipoxygenase-activating protein is an arachidonate binding protein. FEBS (Fed. Eur. Biochem. Soc.) Lett. 318:277281.

34. Brock, T. G., R. Paine III, and M. Peters-Golden. 1994. Localization of 5 -lipoxygenase to the nucleus of unstimulated rat basophilic leukemia cells. $J$. Biol. Chem. 269:22059-22066.

35. Watkins, J., and C. Kent. 1992. Immunolocalization of membrane-associated CTP:phosphocholine cytidylyltransferase in phosphatidylcholine-deficient Chinese hamster ovary cells. J. Biol. Chem. 267:5686-5692.

36. Krek, W., G. Maridor, and E. Nigg. 1992. Casein kinase II is a predominantly nuclear enzyme. J. Cell Biol. 116:43-55.

37. Matsumoto, T., C. D. Funk, O. Radmark, J.-O. Hoog, H. Jornvall, and B. Samuelsson. 1988. Molecular cloning and amino acid sequence of human 5lipoxygenase. Proc. Natl. Acad. Sci. USA. 85:26-30.

38. Dixon, R. A. F., R. E. Jones, R. E. Diehl, C. D. Bennett, S. Kargman and C. A. Rouzer. 1988. Cloning of the cDNA for human 5-lipoxygenase. Proc. Natl. Acad. Sci. USA. 85:416-420. 